\title{
Cancer Biology and You: An Interactive Learning Event for Native American High School Students to Increase Their Understanding of Cancer Causes, Prevention, and Treatment, and to Foster an Interest in Cancer-Related Careers
}

\author{
Tyler A. Herek ${ }^{1 *}$, Connor Branick ${ }^{*}$, Robert W. Pawloski ${ }^{3}$, Kim Soper ${ }^{4}$, Liliana P. Bronner ${ }^{5}$, Misty S. Pocwierz-Gaines ${ }^{2}$, \\ Shrawan Kumar ${ }^{7}$, Regina E. Robbins ${ }^{6,8,7^{* *}}$, Joyce C. Solheim ${ }^{2,6^{* *}}$, and Maurice Godfrey ${ }^{6,7^{* *}}$
}

${ }^{1}$ Department of Pathology and Microbiology; ${ }^{2}$ Eppley Institute for Research in Cancer and Allied Diseases; ${ }^{5}$ Department of Family Medicine; ${ }^{6}$ Fred and Pamela Buffett Cancer Center; ${ }^{7}$ Monroe-Meyer Institute; and ${ }^{8}$ Department of Health Promotion, ${ }^{4}$ University of Nebraska Medical Center, Omaha, NE and ${ }^{3} \mathrm{College}$ of Education and Human Development, University of North Dakota, Grand Forks, ND ( ${ }^{*}$ equal contribution; ${ }^{* *}$ Co-corresponding authors)

Keywords: breast cancer, cancer biology, career, high school students, interactive, Native American, skin cancer

Publication Date: September 24, 2019

DOI: https://doi.org/10.15695/jstem/v2i1.16

\begin{abstract}
The National Institutes of Health and the National Science Foundation have made a compelling call to action not only to strengthen the pipeline of available STEM-trained talent, but in addition to foster students who are members of populations currently under-represented in science. Furthermore, the scientific community must not only increase the accessibility of STEM-related education, but also implement and test evidence-based practices. Presented here, we detail the proceedings of a hands-on, science-focused informal learning opportunity aimed at educating an underrepresented population in cancer biology. Fifteen undergraduate and graduate student volunteer instructors from the University of Nebraska at Omaha and the University of Nebraska Medical Center engaged with 89 high school students, mostly Native American, in an informal learning event called "Cancer Biology and You Day." Throughout the event, students completed two independent lessons focusing on breast cancer and skin cancer and demonstrated strong learning gains associated with the lessons as assessed by KWL charts. Exit surveys of the students indicated high levels of satisfaction with the event, and positive attitudes associated with considering a career in science/research were evident in survey responses. Overall, we report the event as a success and outline how similar experiences may be achieved.
\end{abstract}

\section{INTRODUCTION}

Science learning and instruction are dynamic practices that can take place in a formal, traditional classroom setting, as well as in an informal, out-of-school setting (Hofstein and Rosenfeld, 1996; National Research Council, 2007). However, as in practice today, it is still evident that much of the formal learning setting revolves around the isolated ingestion of facts, in what has been described as a "spectator sport" (Tinto, 2003), where students are passively involved in watching instructors give presentations wherein little-to-no engagement is necessary or required. This disconnect creates a culture in which students do not feel as though they have ownership or agency over their learning and causes the disenfranchisement of students whose edu- cation would be better facilitated with group-style learning (Freeman et al., 2014). This disenfranchisement can impact attitudes and retention of students, particularly those interested in the sciences (Osborne et al., 2003). Research has provided evidence that students are more likely to persist in science if they feel the support of a collective group with shared interests (Dennis et al., 2005; Graham et al., 2013). Students have been reported to positively value peer-peer interactions, with this finding being stronger for groups who are at this time under-represented in the sciences (Lopatto, 2004; Chang et al., 2014).

Although the rate at which American Indian/Alaska Native (AI/AN) students start an undergraduate degree is 
similar to that of White students, their attrition rates are reportedly as high as $85 \%$. Moreover, the AI/AN racial ethnic group is the least likely to major in science and engineering among the groups evaluated (Guillory and Wolverton, 2008). AI/AN students lack role models, experience added pressure associated with being the only representative of their race in STEM programs, and suffer from social isolation (Burgess, 2012). Not surprisingly, of the 44,521 U.S. doctorate degrees awarded in science and engineering in 2015, only 137 were awarded to AI/AN students (National Science Board, 2018).

Over the last decade, the National Institutes of Health (NIH) and National Science Foundation (NSF) have sought to correct this disenfranchisement, especially amongst under-represented populations in science, by offering funding for research projects aimed at addressing the "pipeline problem" (Hurtado et al., 2010; Allen-Ramadial and Campbell, 2014). Such projects are tailored to engage underrepresented populations in informal, science-focused activities to help spark students' passion for science. The current literature backs such an endeavor, as informal learning has been shown to engage the critical thinking skills of students and increase their desire to gain additional information about science and related fields (Sheridan et al., 2011; Stake and Mares, 2005; National Research Council, 2010). An example of such an effort, which was sponsored by an NIH grant to the University of Nebraska Medical Center (UNMC) and that served as a model for the event described in this report, was a day-long learning opportunity for Native American high school students that was held to foster understanding of physiology and interest in life science careers (Becker et al., 2017).

There is a particular need for improved health literacy related to cancer in the Native American population. According to the Centers for Disease Control and Prevention, over the past 20 years cancer death rates have not declined as much in AI/AN people as in White people (CDC, 2019), suggesting that Native Americans are not benefitting as much as White people from advances in cancer prevention and/or treatment. Two types of cancer for which there is a need for more education among Native Americans are breast cancer and skin cancer. Northern Plains Native American women with breast cancer and other types of cancer reported having poor patient-healthcare provider relationships and misinformation about therapies (Liddell et al., 2018). Furthermore, in a study by Burnette et al. (2019), 26\% of surveyed American Indian women in the Northern Plains who were survivors of breast cancer and other cancers reported a desire for more cancer education. A sample population of Northern Plains Native American women was also found to have fewer screenings for breast cancer than the rest of the population (Holm et al., 2010). Likewise, in a study conducted in Arizona, Native Americans were noted to have screenings by dermatologists for skin cancer at a very low frequency, and to use sunscreen less than Whites (Maarouf et al., 2019). Minority populations, including Native American people, have a relative lack of awareness of melanoma compared to White people (Shoo and Kashani-Sabet, 2009). Among Oklahoma Native Americans, compared to White people, melanoma tends to be diagnosed at a worse stage, which suggests that education for Native Americans about skin cancer could be crucial for increasing detection of melanoma cases at a more treatable point in the disease (Baldwin et al., 2016). Skin cancer diagnosis at an advanced stage has also been noted for Southwestern Native Americans (Black and Wiggins, 1985). Among pediatric melanoma patients in New Mexico, the American Indian children had worse disease at diagnosis than either Hispanic or non-Hispanic White patients (Rajput et al., 2014).

For over twelve years, UNMC has cultivated partnerships with schools and communities on six Indian reservations in Nebraska and South Dakota via a National Institutes of Health Science Education Partnership Award (SEPA)-sponsored program. The cooperative relationships we have built over time in these communities enables the implementation of innovative approaches to science instruction, enriching the educational experience for students. Our UNMC Youth Enjoy Science (YES) Research Education Program is a program funded by the National Cancer Institute that aims to encourage partnerships among biomedical scientists, science educators, and community leaders to provide cancer education and to increase the number of Native American cancer research and health care professionals. Therefore, the UNMC YES Program activities are focused on enhancing the diversity of the biomedical workforce by holding cancer-related educational activities. In this report, we present findings from a UNMC YES Program hands-on, cancer-focused informal learning opportunity aimed at serving Native American high school students. We assessed whether the participation in this informal cancer biology learning opportunity had a positive impact on short-term student learning gains and their perceptions of cancer, and if any of the students expressed a desire to pursue a career field related to research, medicine, and/or cancer after participating in the activities of the day.

\section{METHODS}

Institutional Review Board. All protocols and data collections were systematically collected about the activities and outcomes of the specific program event to contribute to continuous improvement and inform future program development. Thus, this study was approved by the UNMC Institutional Review Board as an educational exempt program assessment. All administered surveys were voluntary, and identities anonymized prior to electronic upload and analysis. 
Material and Instructor/Facilitator Preparation. A group of 15 volunteers consisting of undergraduate $(n=5)$ and graduate $(\mathrm{n}=10)$ students participated as instructors/facilitators for this event. The five undergraduates were from the University of Nebraska at Omaha (UNO) Native American Studies program's service learning course in Native American Health and Wellness. These undergraduates had previously dedicated over two months to studying Native American cultural influences on health and wellness, including cancer health disparities issues. One of the graduate students was an M.S. student in the UNO Biology Department, and the other nine were Ph.D. students at the UNMC Fred and Pamela Buffett Cancer Center $(\mathrm{n}=9)$. These volunteers were recruited to participate by UNO and UNMC faculty members via targeted email invitations sent to students in the UNO Native American Health and Wellness course and the UNMC Cancer Research Ph.D. Program. A few of the Cancer Research Program students who decided to participate then invited students in other UNO/UNMC graduate programs who they knew had an extensive knowledge of cancer biology and an interest in education. Three of the 13 volunteer instructors (two undergraduate and one graduate student) and one of the faculty members who participated in this event identified as Native American.

Approximately one month prior to the event, one UNO faculty member, three UNMC faculty members and all the volunteer instructors attended an instructional meeting in which a UNMC YES Program educational consultant familiarized the volunteer instructors with strategies to engage students in science-based dialogues (e.g., on science career opportunities, continuing education, and professional development). The educational consultant also introduced the volunteers to materials produced by Science Take-Out, LLC (Honeoye Falls, NY). Faculty and volunteer instructors formed small groups and engaged in a hands-on, collaborative exploration of the two Science Take-Out, LLC science activity kits chosen to be used with high school students at the "Cancer Biology and You Day", which were "Breast Cancer Risk: Genes and the Environment" (\#STO-146) and "A Case of Skin Cancer" (\#STO-149). As noted in the Introduction, there is a serious need for better cancer literacy relevant to both breast and skin cancer among members of the Native American population, and hence these specific activities were appropriate and useful for our outreach event in terms of content. The educational coordinator for the UNMC YES Program was familiar with the general characteristics of Science Take-Out kits and their high quality and ease of use, and had suggested them as a source of activities that would be suitable for the high school age group and of the correct duration for a day-long event. Before confirmation of the choice of these specific activities, the educational coordinator and some of the faculty and staff members in the UNMC YES Program read the teachers' materials for the ac- tivities and discussed them. Thus, after consideration, these materials were selected to foster high school student engagement and discussion about cancers at the "Cancer Biology and You" event.

All of the graduate student volunteers were trained on content for the event. Previous to this training, from their Ph.D. (or M.S., in the case of one student) studies, these graduate students had a thorough background in basic, translational, and clinical cancer concepts. The undergraduate volunteer instructors were trained in the science activity content in relation to material in the UNO Native American Health and Wellness course. This course had provided these students with an overview of the ways that American Indians combine the best of traditional and modern medicine to address illness, suffering, medicine, healing, recovery and wellness. By contextualizing Native American wellness and cancer, in particular, with respect to Indigenous worldviews, traditional values, and Native wellness models, this course asked students to examine historical and social conditions that have contributed to current health disparities resulting from colonization and to consider cancer in relation to physical, mental, spiritual, and contextual dimensions of wellness.

The evening before the event, faculty and volunteer instructors were given a tour of the event venue, a 40,000 square foot facility at the Delta Hotels by Marriott on the Riverfront in South Sioux City, NE. All faculty and volunteer instructors were assigned stations, and were asked to set up their stations as they deemed appropriate. Instructors set up 11 learning group stations (small group settings wherein 1-2 instructors could engage with 4-8 students). A final question and answer session (attended by faculty, instructors, and staff members) was held to address last minute inquiries. In addition, on the evening before the event, a tribal elder of the local Winnebago Tribe of Nebraska spoke to all the volunteer student instructors (both non-Native and Native American), as well as to the staff and faculty, about the value of health research and education to the Native American people and about specific health issues that are especially relevant to Native Americans in eastern Nebraska.

Details of the Event. Eighty-nine registered student attendants, mostly Native American, attended the event, accompanied by their teachers. The group was comprised of students from five schools on Native American Reservations in Nebraska and South Dakota. The exact number of students who were Native American is not known, since the attendees were not required to identify their race; however, most of the partner schools invited have a student population that is $>95 \%$ American Indian. The invitation issued to the schools by the UNMC YES Program did not specify any subset of students (e.g., science class students); whether the schools selected specific subsets of students to bring to the event is 


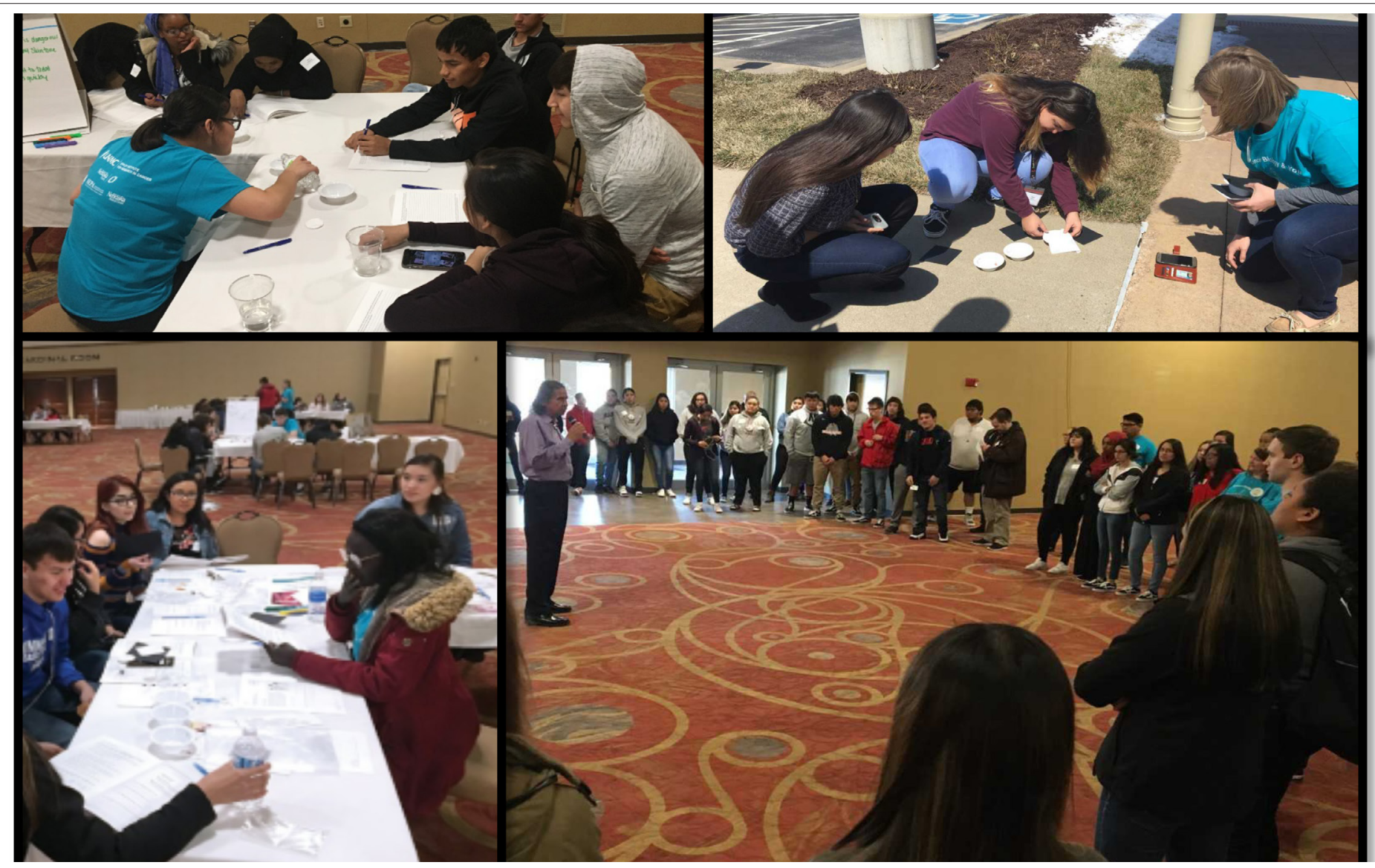

Figure 1. Photographs of some of the students and volunteer instructors who attended the "Cancer Biology and You Day" event are displayed.

unknown. Prior to this event, UNMC faculty and staff had been engaged in science education outreach to these specific schools through a variety of projects since 2006 , funded by an NIH SEPA grant, and several of these same faculty and staff members participate in the UNMC YES Program. Furthermore, representatives from reservation schools are members of a UNMC YES Program External Advisory Board that meets three times per year (at a location close to the schools) to get input from the schools and to plan events according to their needs and schedules. Therefore, the teachers and administrators at these schools were very supportive of partnering with UNMC in this event.

Students were semi-randomly assigned to one of 11 instructor-led groups, with an effort to split students from the same school, age, and gender. The instructors maintained their association with the same group throughout the day and did not rotate among groups, in order to allow more development of rapport between them and their students. Students arrived at the site around 9:00 a.m. and were checked in and guided to their groups. Before beginning activities, a tribal elder (the same one who had spoken to the instructors, staff, and faculty the evening before the event) offered a welcome message and blessing, reminding the students that they were there for an important reason and encouraging them to make the most of their experience (Figure 1, lower right panel).
The tribal elder remained at the site and circulated among the student groups throughout the day while the event was taking place. At 9:30 a.m., the students began to work on their activities, receiving directions and assistance from the instructors (Figure 1, upper panels and lower left panel). Approximately 90 minutes were allotted for students to complete each kit-based activity. Students were given a 15-minute break in the mid-morning session and a 50-minute on-site lunch break (with box lunches provided for them). Students' activities for the day concluded with taking post-event surveys and then posing for a voluntary group photograph at approximately 2:00 p.m. The amount of time available for completion of the survey varied slightly, as some groups finished a few minutes earlier than others, but all students had at least 10 minutes for survey completion. The students then were bussed back to their respective schools. The instructors proceeded to pack up the materials from the stations and ended the event with a quick recap before leaving the site, sharing reflections on the day.

Details of the Learning Activities. During the morning and afternoon sessions, the students engaged in a hands-on, guided exploration of two distinct science activity kits produced by Science Take-Out, LLC (Honeoye Falls, NY). In the morning session, students completed the "Breast Cancer 
Risk: Genes and the Environment" (\#STO-146) activity kit. In the afternoon session, students completed the "A Case of Skin Cancer" (\#STO-149) activity kit. A brief description of these kits is found below, and full information can be found on the manufacturer's web page (www.sciencetakeout.com).

Breast Cancer Risk: Genes and the Environment. Students were presented with the scenario of a young woman learning of her family history of breast cancer. In this activity, the concept of gene inheritance, particularly the inheritance of a mutated $B R C A 1$ gene, was introduced. The first section was dedicated to understanding a pedigree. Next, genetic tests were discussed with the students while they performed their own simulated, stain-based genetic test to identify simulated family members with a mutated $B R C A 1$ gene. The second half of the activity was centered on understanding the current literature of risk factors, specific risk factors for breast cancer, and how the environment can play a role in the development of breast cancer. The main thematic elements from this activity were delineated as: 1) the role of genetics/inheritance in breast cancer (specifically detailing $B R C A 1$ involvement), and 2) other risk factors for breast cancer. In regard to information about careers related to cancer, in its narrative this lesson presented the concept of genetic testing for evaluation of cancer risk (though the job title of the person performing such tests was not specified) and it included stories of research by public health scientists to assess the contribution of DDT to breast cancer risk.

A Case of Skin Cancer. In this lesson, the students were introduced to a young woman who, at the urging of her friends, visits a dermatologist for removal of an abnormal mole. Upon biopsy, the mole is determined to be cancerous. The lesson is set up as a mock diary of the girl, noting her initial diagnosis, a follow-up indicating the presence of metastasis, chemotherapy, and remission. Next, students learned the importance of obstructing ultraviolet (UV) light for skin cancer prevention by using UV beads to design and conduct an experiment to test for the optimal way to protect oneself from harmful UV rays. Finally, each group of students created an infographic centered on skin cancer and sun safety that was presented to the entire assembly. The main thematic elements from this activity were defined as: 1) the identification and classification of abnormal moles, and 2) the importance of blocking UV rays with sunscreen to reduce the risk of skin cancer. In this activity, information was also provided to the students about cancer-related careers. In the skin cancer story, the role of a dermatologist in removing an abnormal mole and submitting it to a lab for diagnosis was introduced. The role of the oncologist in prescribing cancer therapy was also presented to the students in this activity.
Assessment Practices and Data Analysis. Two assessment strategies for the students were utilized to measure both group-based learning and individual learning. These strategies allowed the researchers to determine if there existed a gain-of-knowledge in the desired content area, how fully the students were able to relay important concepts back to the instructors, and if there was a desire by the students to follow science/cancer-related careers after activity completion. The first assessment employed a KWL chart (KWL is an abbreviation for "Know, Want to know, and Learned") (Carr and Ogle, 1987). The assessment is designed so that students can visualize what they already know about a topic, ask questions about that topic that they want to have answered, and state what they learned about the topic after the lesson. Before starting the lessons, each student group was asked to write, in the " $\mathrm{K}$ " column on an easel pad, what they already knew about breast and skin cancers (for $\sim 10$ minutes). To trim the time required and to optimize the clarity, we revised the assessment by omitting the "W" portion from the information to be charted. At the conclusion of each activity, each group wrote what they had learned about breast and skin cancers under the "L" column to track their learning progress (for $\sim 10$ minutes). All student input was accepted and reported on the chart, particularly in the " $\mathrm{K}$ " sections, but consensus was frequently reached within groups in the "L" sections. An advantage of KWL charts is that they elicit active participation from many students; however, a disadvantage is that not all students wish to participate actively, though tend to do so when asked directly to contribute. The instructors endeavored to foster equal participation by all the students, and answered questions and provided clarifications to students whenever necessary during the process.

Although each of the 11 groups engaged in making a KWL chart for each activity, not all groups completed every portion of each of the charts. Incomplete charts were due to volunteer instructor errors in time management over the course of the activities. (There were no evident differences among groups that did complete versus did not complete the charts. Before similar events will be undertaken by the UNMC YES Program in the future, the importance of monitoring the time frequently to ensure completion of KWL charts will be emphasized to the instructors during training.) Only fully completed charts (i.e., with a completed "K" and "L" section) were considered for analysis. To analyze the qualitative information from the KWL chart, we assessed the presence or absence of the two thematic elements per activity kit (the themes stated above in the "Breast Cancer Risk: Genes and the Environment" and "A Case of Skin Cancer" sections). Two researchers scored group answers by consensus based on the presence or absence of these themes as recorded on the KWL chart. Answers scored " 0 " if no portion of a vital theme was recorded on the chart, 0.5 if half of a vital theme was recorded (e.g., indicating the sun can cause 
skin cancer, but no mention of the involvement of UV rays in the process), and 1 if the group displayed full knowledge of the theme on their KWL chart. Each chart displayed the two respective themes per lesson to visualize the progress made. Comparison of Know and Learn scores were conducted using the Mann-Whitney U test with the hypothesis that completion of learning activities will lead to a gain-ofknowledge in the desired content areas. Interrater reliability was not assessed.

In addition to the KWL chart, the second form of student assessment was a brief survey, including two multiple-choice questions per activity kit and with four open-ended questions. The survey was prepared by the UNMC YES Program evaluation consultant, with input from the faculty and staff involved in the UNMC YES Program, based on consideration of what information would be useful to acquire to assess the impact of the event on the students' learning about the topics and their future career plans. The multiple-choice questions were "The Breast Cancer Lab captured my interest," "The Breast Cancer Lab introduced me to new information regarding cancer," "The Skin Cancer Lab captured my interest," and "The Skin Cancer Lab introduced me to new information regarding cancer," with the following answer options: "strongly agree," "somewhat agree," "neither agree nor disagree," "somewhat disagree," and "strongly disagree." The four open-ended questions were "What was the best part of today's activities?," "What might the orga-

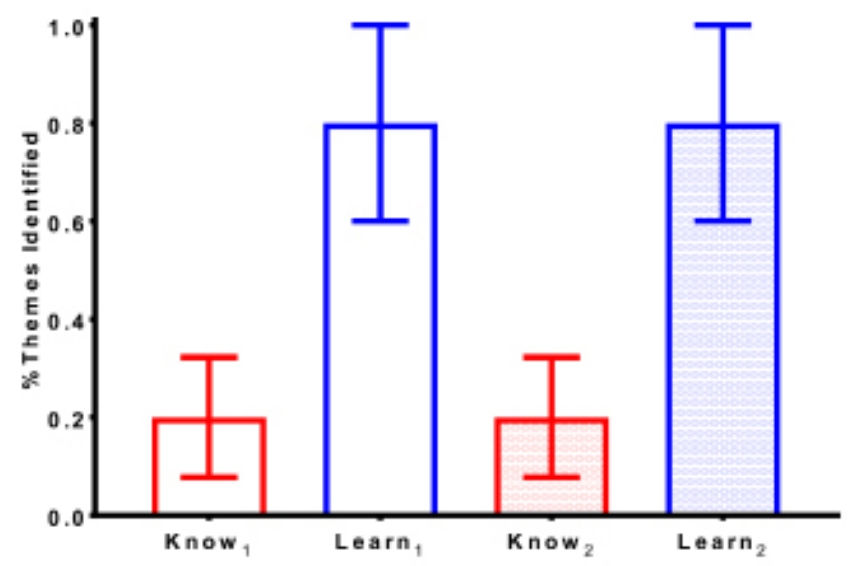

Figure 2. The students demonstrated breast cancer learning gains, as shown by analysis of the KWL charts. Each of the 11 groups were assessed on their before and after knowledge of two themes on a scale of 0 to 1 . The two themes considered vital were: 1 ) the role of genetics/inheritance in breast cancer (focusing on BRCA1 mutations), and 2) additional types of risk factors for breast cancer. The "Know," and "Learn," bars in the graph illustrate what the students knew before versus after the breast cancer activity about the genetic inheritance of breast cancer, especially as related to the $B R C A 1$ gene. The "Know ${ }_{2}$ " and "Learn," bars in the graph compare what the students knew about other breast cancer risk factors before the activity compared to after the activity. nizers of the "Cancer Biology and You" event consider to improve future events such as this? (You may comment on facilitators, activities, materials, facility, etc.)," "What ideas can you take away from today about potential careers for you?," and "In very simple terms, please provide a brief description of how you would explain to a friend or family member what you experienced today at "Cancer Biology and You"." Students were asked to complete this survey at the end of the day. The individual surveys were completed voluntarily by 81 of the 89 students. To analyze the survey questions, multiple-choice questions were analyzed quantitatively and graphed directly from the data and short answer responses were analyzed qualitatively by the researchers and coded into emergent themes by directed categorization (Hsieh and Shannon, 2005).

The undergraduate and graduate student instructors were also given a survey after the event, which 13 out of 15 instructors completed. The three questions on the survey were "Overall, how would you rate your experience as a facilitator at the "Cancer Biology and You" event?," "In very simple terms, please provide a brief description of how you might explain to a friend or family member what you experienced at this event," and "What is your current career path, and how might today's experience impact your future work?"

\section{RESULTS}

\section{Student Learning Gains Following the Interactive Breast}

Cancer Lesson. In Figure 2, it is shown that before undertaking the breast cancer activity most of the students did not even know that a $B R C A 1$ gene mutation correlated with breast cancer. Even more strikingly, prior to the activity, most students were unaware that risk factors in the environment could lead to breast cancer. Specifically, before beginning the breast cancer activity, only $45 \%$ of KWL charts indicated genetics as playing a role in breast cancer $(n=5 / 11$, $\mathrm{Mdn}=0,2.5$ total vital theme score [aggregate value]), with no charts mentioning BRCA1 $(\mathrm{n}=0 / 11, \mathrm{Mdn}=0,0$ total vital theme score) (Figure 2). However, after completion of the breast cancer activity, all groups ( $\mathrm{n}=11 / 11,11$ total vital theme score) successfully linked breast cancer to an inheritable disease through the $B R C A 1$ gene, demonstrating an increase in the Learn score $(U=0, \mathrm{p}<0.01)$. Students' knowledge of risk factors that can contribute to breast cancer development also increased after participation in the group activities. Initially, $18 \%$ of the KWL charts $(n=2 / 11$, Mdn $=$ 0,1 total vital theme score) indicated knowledge of risk factors leading to breast cancer and no groups provided specific examples. However, upon completion of the breast cancer activity, groups showed a significant gain $(U=0, \mathrm{p}<0.001)$ in their knowledge of risk factors by identifying correctly various risk factors linked to breast cancer $(n=11 / 11$, Mdn $=1,11$ vital theme score). 


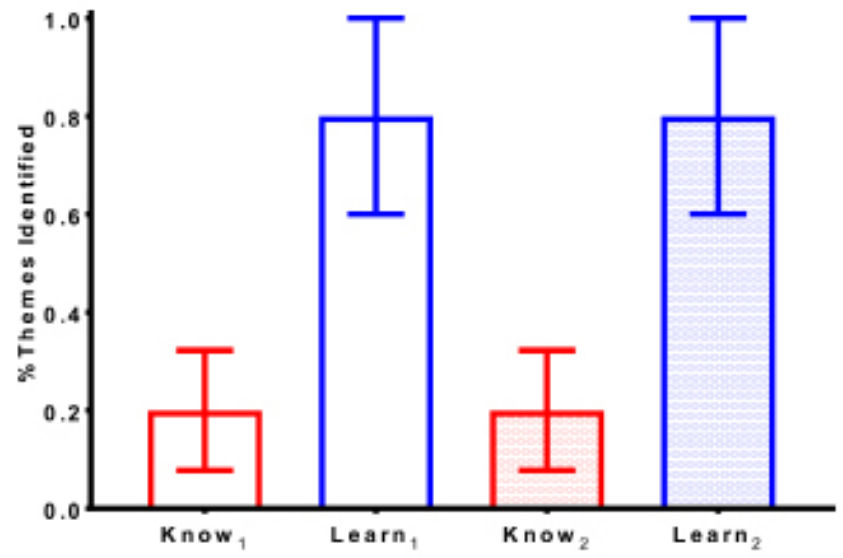

Figure 3. The students displayed skin cancer learning gains, as indicated by the data in the KWL charts. Each of the 11 groups were assessed on their before and after knowledge of two themes on a scale of 0 to 1 . The vital thematic elements from this activity were: 1) the identification and classification of abnormal moles, and 2) the importance of using sunscreen to block UV rays to reduce skin cancer risk. The "Know1" and "Learn." bars in the graph illustrate what the students knew before versus after the skin cancer activity about the identification and classification of abnormal moles. The "Know2" and "Learn2" bars in the graph compare what the students knew about the importance of blocking UV rays with sunscreen to prevent skin cancer before the activity compared to after the activity.

Student Learning Gains Following the Interactive Skin Cancer Lesson. For the skin cancer activity, the student KWL charts were assessed for indicators of knowledge of how to check for and identify potentially cancerous moles, and for an understanding of UV exposure and risks for skin cancer (Figure 3). Of note, $n=6 / 11$ groups failed to complete a matched "K" and "L" portion of the KWL charts and were omitted. (A matched KWL chart was defined as a completed chart with both $\mathrm{K}$ and L sections present.) The KWL charts indicated that prior to engaging in the activity, some students had an understanding of the association between skin cancer and moles, as well as the association between skin cancer and sun exposure $(n=2 / 5, \operatorname{Mdn}=0,1$ total vital theme score). However, no group provided information about identifying potentially cancerous moles or about UV rays specifically. Following the activity, the groups showed significant $(U=3.5, \mathrm{p}=0.039)$ improvements in their knowledge of these themes. However, not all groups provided information on how to check for suspect moles $(\mathrm{n}=4 / 5, \mathrm{Mdn}=1,4$ total vital theme score), nor on the importance of protection against $\mathrm{UV}$ radiation from the sun $(\mathrm{n}=4 / 5, \mathrm{Mdn}=1,4$ total vital theme score).

Student and Instructor Attitudes Towards Careers. General information about opportunities in cancer-related education, treatment, and research available at UNMC was very briefly provided to the students at the beginning of the event by a faculty member, and the tribal elder who spoke to the students at the beginning of the event noted the importance of health care to the Native community. During interactions between students and their instructors (in the course of the activities and during the shared lunchtime), the students had time to ask their instructors about education and career options. This unstructured benefit allowed for considerable discussion about science-related careers. These discussions between students and instructors clarified many aspects about career avenues that would otherwise have remained unclear and ambiguous to the students. Evidence that the students extended their conversations beyond the specific activities of the lesson was provided by anonymous survey responses by the instructors following the event. In response to this question: "In very simple terms, please provide a brief description of how you might explain to a friend or family member what you experienced at this event," in addition to describing the cancer content of the event, the instructors had responses such as "We filled the extra time with talking about some of the cellular fundamentals of cancer and college," "Helped students learn some more about cancer risks

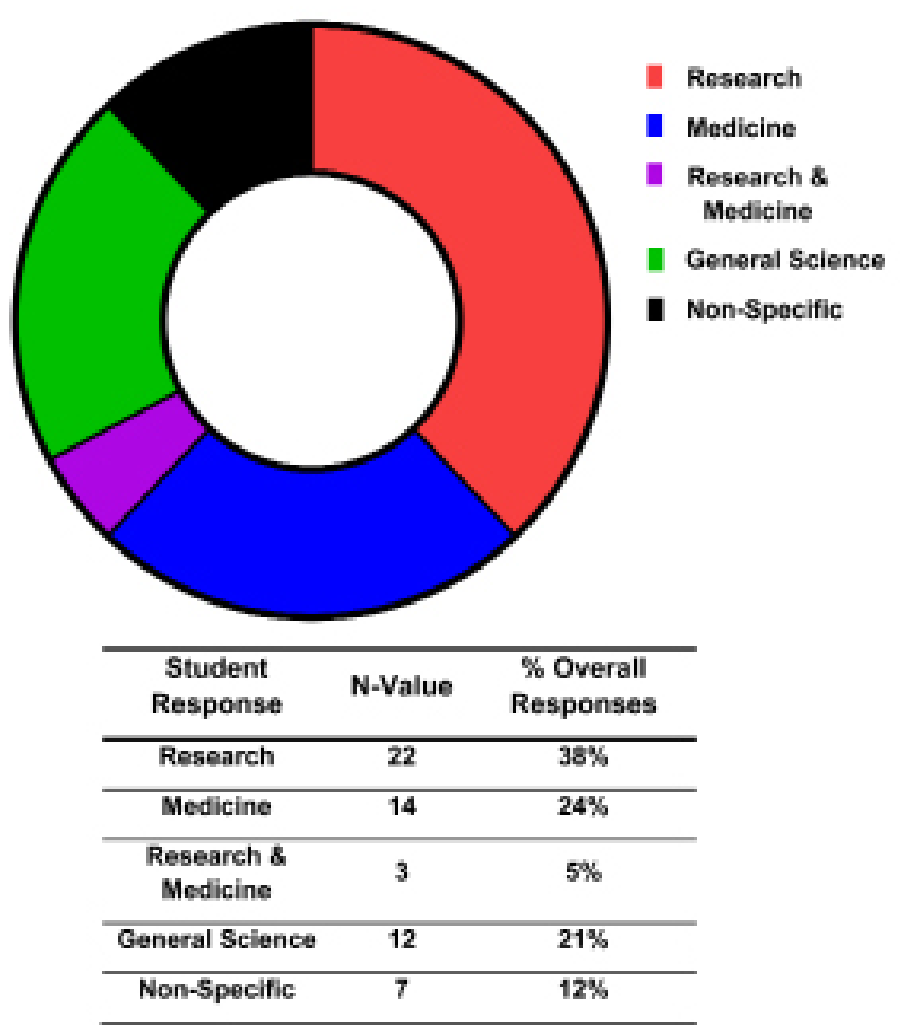

Figure 4. Many students' responses to the question about potential career choices indicated an interest in research, medicine, and science careers. The students were asked to provide a short answer to this question: "What ideas can you take away from today about potential careers for you?." The responses were then put into relevant categories. For example, students who wanted to be a nurse or oncologist were grouped into the medicine category while those who wanted to work in a research lab were grouped under research. The category "Non-Specific" was used for those who answered with a non-determinant response. 
and prevention, while answering any questions they had about my career path so far," and "I interacted with students about some basic things regarding cancer and its prevention and ways they can explore this field."

In the exit survey given following the activities of the day the students were asked: "What ideas can you take away from today about potential careers for you?." After the "Cancer Biology and You Day," filled with experiments, 38\% (n $=22 / 58$ ) said they would consider a career as a scientist (Figure 4). The denominator is 58 rather than 81 because 15 students skipped the question and 8 students gave answers that were entirely unrelated to careers but indicated that the skin cancer lesson would influence their personal health behavior. For example, one such answer was "wear sunscreen". The students who skipped giving responses did not have significantly different answers from those that completed the entirety of the assessment. A lower response rate on the career question was likely due, in part, to the fact that it was a fill-in-the-blank question, which would require more thought and time to answer, whereas the other questions were in multiple-choice format. In addition to the high interest in a scientist/research career mentioned by students, several students showed interest in becoming a physician or in other science-related fields. A small proportion (5\%) of the students expressed a desire to enter into a career involving both medicine and science. The remaining students $(12 \%)$ gave answers about interests that were not specific to entering a career in research, medicine, or science.

Furthermore, in response to the question "What ideas can you take away from today about potential careers for you?," not only science but specifically cancer was a prevalent theme in the student responses. Twenty-five students mentioned the word "cancer" in their answer about a career that they were now considering, and of those 18 mentioned a career that included cancer research. Of those students who mentioned a career that included cancer research, two specified research in cancer "cure," four mentioned a career related to cancer prevention (e.g., "How to help reduce the risk of getting cancer"), and one mentioned both ("It's important to learn about risk factors of cancer and learn how we can improve on treatments"). Two students specifically mentioned "dermatologist" or "dermatologist or a cancer researcher" in their answers, and one student answered "Go to school and become an oncologist." Notably, the crucial roles of dermatologists and oncologists in cancer diagnosis and treatment were presented to students in the skin cancer lesson. Furthermore, of the three students who expressed interest in nursing as a career, one made a connection with nursing and sunscreen protection ("I want to be a pediatric nurse so maybe use sunscreen protection more when dealing with kids"), and another mentioned that as a nurse he/she could point out abnormal lesions to patients ("I can see how the types of skin cancer look like and if something seems wrong tell patient to go check it out before too late.”) Thus, the event was highly successful in sparking student interest in science/medicine, and specifically in a variety of cancer-related careers.

The "Cancer Biology and You Day" event also had an impact on the instructors' concepts of their future career planning and preparation. In their survey, the instructors were asked "What is your current career path, and how might today's experience impact your future work?" Three of the instructors who responded to the survey did not provide an answer to this question, but all the others responded that it had increased their interest and/or ability to teach/communicate in academic and/or clinical settings. For example, one instructor stated, "After today, I would like to integrate teaching into my studies more often, especially among high school students and those of diverse backgrounds." Another response was "I had not considered teaching in the past, but may consider it in the future after today's experience as I enjoyed using my knowledge and experience to educate and po-

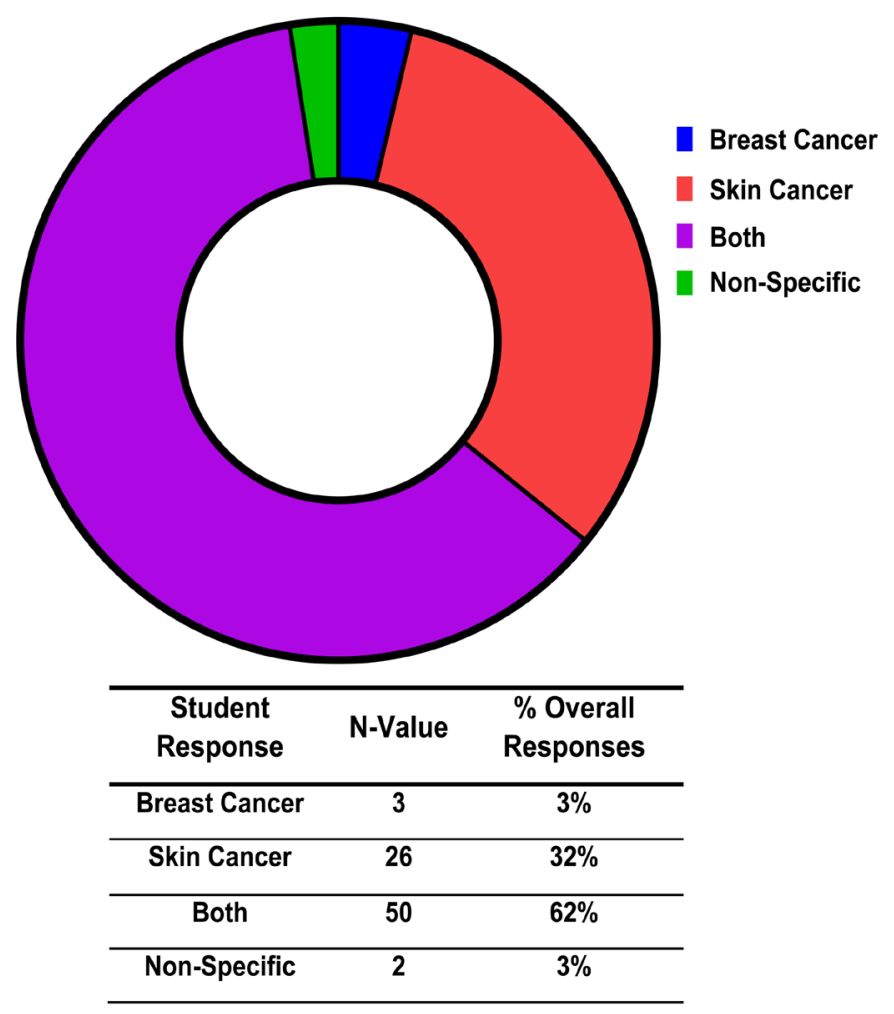

Figure 5. Students' responses indicated that they enjoyed both activities but preferred the skin cancer activity. The students were asked to provide a short answer to this question: "What was the best part of today's activities?." The responses were then put into categories (Breast Cancer, Skin Cancer, both, or non-specific).

tentially influence others." One of the instructors said, "This experience helped me become a better educator." Another instructor noted, "This impacts my future by helping me to more easily discuss malignancies and information about them (with) non-scientific audiences." In response to being asked "Overall, how would you rate your experience as a fa- 


\section{A}
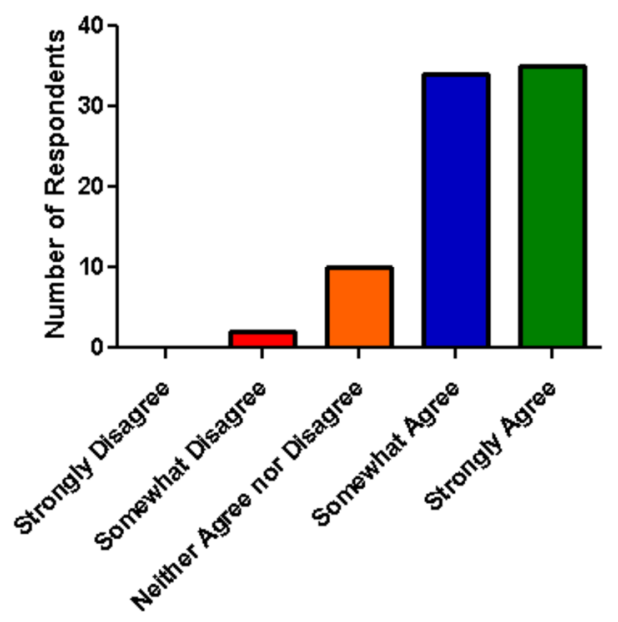

C

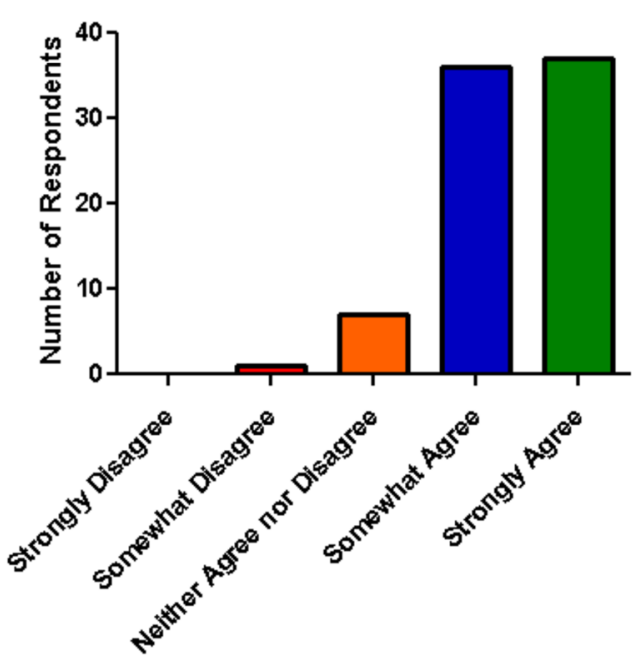

B
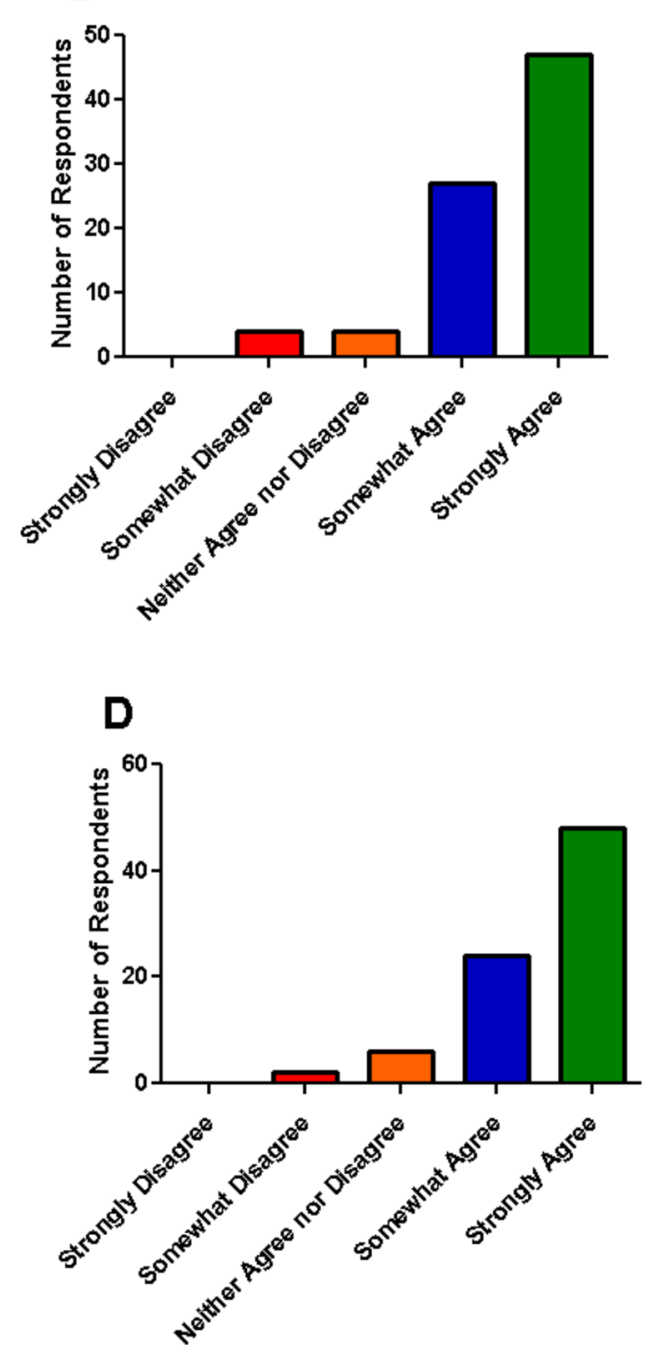

Figure 6. The students' responses to the statements (A) "The Breast Cancer lab captured my interest," (B) "The Breast Cancer lab introduced me to new information regarding cancer," (C) "The Skin Cancer lab captured my interest," and (D) "The Skin Cancer lab introduced me to new information regarding cancer" indicated that high proportions of the students agreed with each of these statements.

cilitator at the "Cancer Biology and You Day" event?," 8/13 survey answers were "Excellent," three were "Very good," and two were "Good." Thus, in general the instructors were very pleased with their experience and viewed it as assisting in their career choice and development.

Enjoyment of the Learning Activities. In the exit survey, the students were also asked the question: "What was the best part of today's activities?." The majority of students (n $=50 / 81,66 \%$ ) did not select one single favorite activity, instead indicating that they enjoyed both the breast cancer and skin cancer activities equally (Figure 5). A large proportion of students $(n=26 / 81,32 \%)$ identified the skin cancer activity as their favorite, and $4 \%(n=3 / 81)$ identified the breast cancer activity as their favorite. The difference in enjoyment of the breast cancer activity versus the skin cancer activity was likely due to the characteristics of the two activities, in that the breast cancer activity was completed entirely with the students sitting inside at tables, whereas the skin cancer activity included a period of time that the students spent outside in the sunshine performing a hands-on experiment (Figure 1, upper right panel).

In addition to indicating their preference for the skin cancer activity over the breast cancer activity, the students' phrasing of the answers to the question "What was the best part of today's activities?" emphasized their particular enjoyment of active aspects of the event. Fifty-one of the 81 students used the words "lab" (or "labs") or "experiment" (or "experiments") in their answer to this question (e.g., "I liked the experiments the most"). Of those 51, there were 14 who included a verb such as "doing" or "did" (e.g., the answer included not just "the experiments" but "doing the experiments"). Six students used the term "hands-on" (e.g., in "hands-on activity," "hands-on lab," or "hands-on experiment"). The use of verbs such as "doing" and the inclusion of the "hands-on" description indicate the importance of phys- 


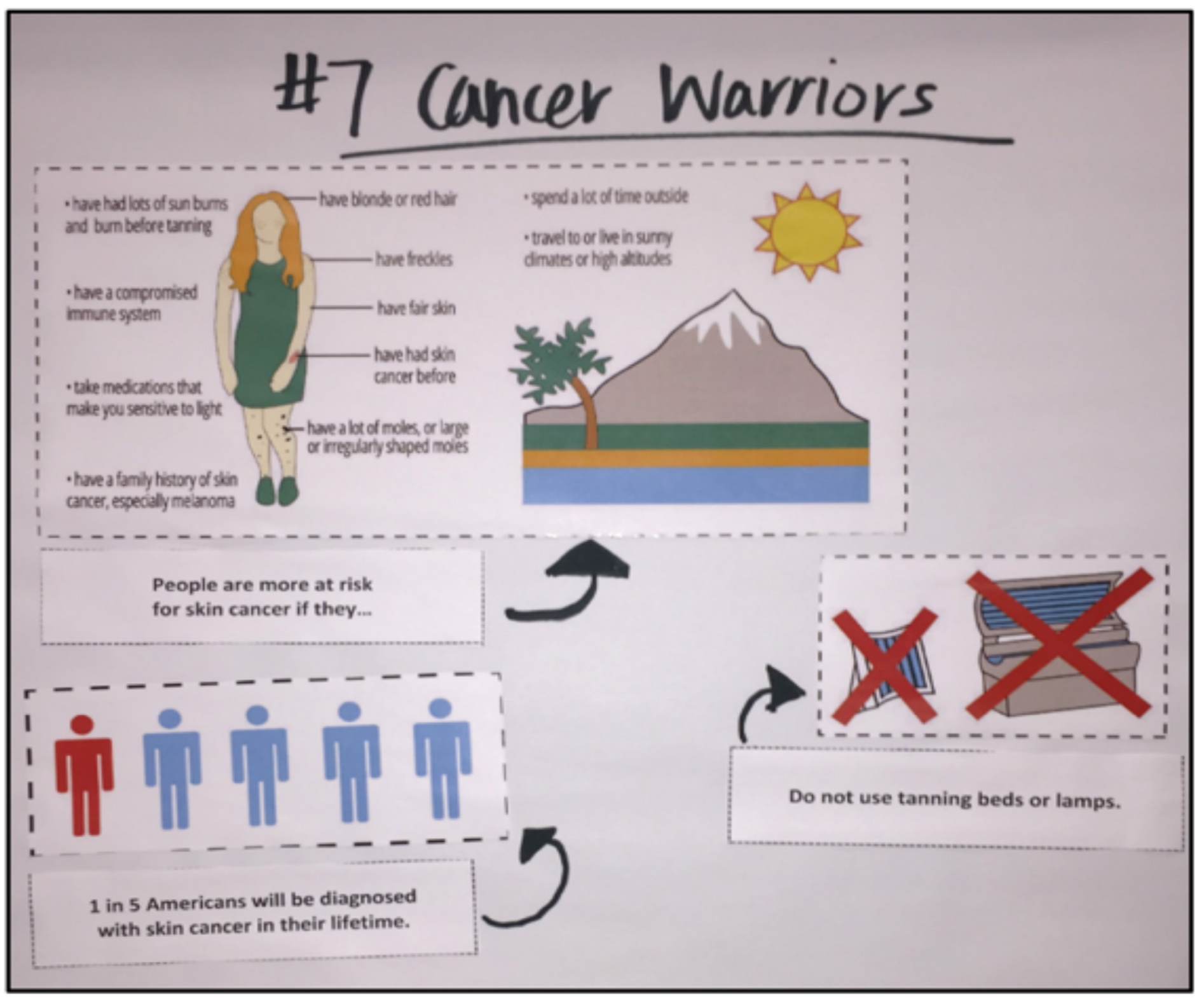

Figure 7. A picture is shown of a representative skin cancer infographic completed by one of the groups, using materials from the skin cancer activity kit.

ical involvement in the event to the students. In contrast, a smaller number (15 students) gave answers that did not have words such as "experiment" or "lab" but instead included "learning" or "talking" or "understand" (e.g., "learning more information about skin cancer," "talking about breast cancer," or "it helped us understand cancer better"). Thus, for some students (15/81), the content itself seems to have been more enjoyable than the process. Two students mentioned both the "lab/experiment" and the "learning" (e.g., "doing the experiments was very fun and I learned a lot"), and two students expressed broad satisfaction with the event (e.g., "everything," "all of it").

Self-Assessment of Interest Level and New Information Learned in the Breast Cancer Activity. The students were given multiple-choice questions for self-assessment of their interest and acquisition of knowledge, as related to the breast cancer activity. Each question had five potential answers, ranging from strongly disagree to strongly agree. In response to the statement "The Breast Cancer lab captured my interest," $n=35 / 81$ students ( $43 \%)$ said that they strongly agreed and $n=34 / 81$ students $(42 \%)$ said that they somewhat agreed that the activity captured their interest. However, $n=10 / 81$ students $(12 \%)$ did not agree nor disagree that the activity captured their interest. Only two students (2\%) somewhat disagreed that the activity captured their interest, and no one strongly disagreed with the statement (Figure 6A). When asked to respond to the statement "The Breast Cancer lab introduced me to new information regarding cancer," $n=44 / 79$ students (56\%) strongly agreed and $\mathrm{n}=27 / 79$ students (34\%) somewhat agreed. There were $n$ $=4 / 79$ students $(5 \%)$ who were neutral about whether they 
had been introduced to new information regarding cancer, while another four students somewhat disagreed (and none strongly disagreed) (Figure 6B).

\section{Self-Assessment of Interest Level and New Information} Learned in the Skin Cancer Activity. Among those who participated in the skin cancer activity, $n=37 / 81$ students $(46 \%)$ said that they strongly agreed and $n=36 / 81$ students (44\%) said that they somewhat agreed with the statement "The Skin Cancer lab captured my interest." However, $\mathrm{n}=$ $7 / 81$ students $(9 \%)$ did not agree nor disagree that the activity captured their interest. Only one student (1\%) disagreed that the activity captured their interest, and no one strongly disagreed that the activity captured their interest (Figure 6C). When asked to respond to the statement "The Skin Cancer lab introduced me to new information regarding cancer," $\mathrm{n}=$ $48 / 80$ students $(60 \%)$ strongly agreed and $n=24 / 80$ students (30\%) somewhat agreed. $\mathrm{N}=6 / 80$ students $(8 \%)$ were neutral about whether they had been introduced to new information regarding cancer from the activity while $n=2 / 80$ students $(3 \%)$ somewhat disagreed with the statement (and no students strongly disagreed) (Figure 6D). As part of the skin cancer activity, each student group generated an infographic focused on skin cancer and sun safety that was shown and verbally described, as a means to reflect on the learning and to share it with all the other student groups (an example of an infographic produced by the students is shown in Figure 7).

\section{DISCUSSION}

Actively engaging Native American students and mentors (including some mentors who were racially/ethnically matched with the students) in hands-on, group style learning through the "Cancer Biology and You" activities resulted in increased aggregate student knowledge of breast and skin cancer biology and prevention. As students worked through the interactive science kits provided at the "Cancer Biology and You" event, they encountered examples and problems that forced them to think critically about this disease and approach each situation from a scientific perspective. By the end of the day, their knowledge of cancer increased. Moreover, participation in this event promoted students' career interests in health care and research professions. The students reported a high level of interest in careers in the medical sciences in the surveys that they completed at the end of the event.

Reflections on the overall experience of Cancer Biology and You point to several important outcomes of interest. First, the students gained knowledge specific to identifying indicators of cancer. For example, the ability to identify the $B R C A 1$ gene mutation as highly correlated with breast cancer and the ability to identify specific abnormalities in shape and color of moles as potentially cancerous were notable ad- vances. Second, the students gained knowledge specific to cancer prevention. In particular, the students learned ways to protect themselves when exposed to elements in the environment that pose a risk for developing cancer. Third, the students' awareness of and interest in medicine and science was facilitated as a result of their attendance at "Cancer Biology and You Day." For example, in the lessons the students were exposed to the concept that many professions (e.g., physicians, researchers, public health practitioners) work to fight cancer. The students also acquired information informally from their instructors about science education tracks and biomedical careers. As an additional benefit of the event, the instructors' interest and ability in teaching increased.

"Cancer Biology and You Day" offered Native American students new opportunities to engage with Native American and non-Native American scientists, peers and mentors in interactive hands-on activities that developed the students' interest in science with specific emphasis on cancer. Limitations of our study include the following: the assessments were restricted to group assessments (in the case of the KWL charts) and self-assessments as indicators of student learning, data from some students is missing due to time management errors, and the sample size at the group level is small. Nevertheless, our assessments provide evidence that effective communication, collaboration, and learning were enabled by the engaging and interactive Science Take-Out activities. The students' responses to the query "What was the best part of today's activities?" emphasized the importance to them of the hands-on lab activities and their high level of interest in the experiments.

The self-guided, active learning activities enabled students to take responsibility for their learning and may have contributed to their retention of crucial components of the lesson material, although we do not have direct proof of that connection. Given the students' high level of interest in the learning modules, it is consistent that students' self-perception of their knowledge on the individual subjects increased. Our data suggest that students were interested in learning about the materials and gained knowledge about the subject matter. Student responses to both activities showed their receptivity to hands-on learning materials. Providing the students with the ability to work through their activities, among their peers, at their own pace and to ask questions of the volunteer instructors as needed was successful.

It is promising that at the end of the "Cancer Biology and You Day" event, the students reported a high level of interest in careers in health care professions and research. Increasing the number of minority health care professionals and researchers has been shown to contribute to reducing health disparities (NRC, 2005). A more diverse biomedical workforce can support greater innovation and productivity in collaborative research settings (Thomas and Ely, 1996; Page, 2007). Currently, there is a chronic shortage of Native 
American physicians and other health practitioners (Marcinko, 2016). Increasing the number of Native American students in medical science and practice is crucial to reducing health disparities in disease prevention and treatment.

Based on our experience and our shared reflections following the "Cancer Biology and You Day" event, we recommend the following guidelines for those working to develop hands-on, science-focused informal learning opportunities aimed at serving a population underrepresented in a science-related field:

1.Establish the cultural connections between science and community in a whole group session (e.g., by inclusion of a guest speaker from the community)

2.Use well-prepared science experiment materials (e.g., from Science Take-Out, LLC)

3. Host events in geographical proximity to the target student population

4.Intentionally include racially/ethnically concordant students and instructors

5.Intentionally include mentors/instructors representing interdisciplinary scientific fields (e.g., laboratory-based cancer research, Native American studies, public health)

6.Intentionally pair students with near peers in small groups (King et al., 1998) to extend the discussion and learning beyond the specific activity being undertaken

7. Train instructors in the prepared activities/materials prior to the event

For many reasons, we need to increase the number of underrepresented minority educators, researchers, and practitioners in health and biomedical fields. An event like "Cancer Biology and You Day" encourages future scientists, clinical investigators, and educators among the American Indian population. By establishing a cohort of American Indian students and providing them with research experiences and a group of knowledgeable instructors that includes Native American instructors, we can create a more diverse and productive setting for learning about science, and specifically cancer. Providing students with mentored research experiences develops their research and communication skills (Lopatto, 2004), builds their academic network systems, increases their comfort levels in academic environments (Hunter et al., 2007), and increases their likelihood of pursuing a degree in graduate school (National Research Council, 2005; Eagan et al., 2013). Ultimately, programs like this can stimulate innovation and improve the educational experience by bringing different and relevant points of view to discussions and scholarly activities (Merchant and Omary, 2010).

Admittedly, the impact of a one-time event can only be a limited one. However, we plan repeating the "Cancer Biology and You Day" as an annual event throughout the duration of the National Institutes of Health-funded five-year UNMC YES Program, and perhaps beyond that time as well. In addition to the "Cancer Biology and You Day," the UNMC YES Program has been offering cancer education experiences at UNMC and/or tribal schools to middle school students, high school students, undergraduate students, and teachers. As a result of this "Cancer Biology and You Day" and others that will follow in future years, combined with other outreach efforts of our UNMC YES Program, we anticipate that Native Americans in the Great Plains will have increased involvement in cancer-related research and healthcare. We also expect improvements in cancer literacy and prevention in the Native American communities in the Nebraska/South Dakota region as a future outcome of this YES Program.

\section{AUTHOR INFORMATION Corresponding Author}

Dr. Joyce Solheim, Eppley Institute for Research in Cancer and Allied Diseases, University of Nebraska Medical Center, 986805 Nebraska Medical Center, Omaha, NE 68198-6805. Email: jsolheim@unmc.edu; Phone: 402-559-4539

\section{Author Contributions}

The manuscript was written through contributions of all authors. All authors have given approval to the final version of the manuscript.

\section{FUNDING SOURCES}

Financial support for this work was provided by an NIH/NCI R25 Youth Enjoy Science Research Grant (R25 CA221777), NIH/NIGMS Science Education Partnership Award (R25 GM129170), NIH/NCI T32 Training Grant (T32 CA009476), and the Fred and Pamela Buffett Cancer Center Core Grant (P30 CA036727).

\section{ACKNOWLEDGMENTS}

The authors thank all the volunteers who participated as excellent instructors in this event: Apeu Akol, Raina Barnes, Chelsea Bulock, Stephanie Barbari, Hannah King, Smit Kour, Bobbie McWilliams, Jonathan Ramos-Robles, Jacob Robinson, Irfana Saleem, Ayano Tagami, Liliana Tamayo, and Krysten Vance. (Two of the authors of this manuscript, Connor Branick and Tyler Herek, also served as volunteer instructors.) We are also very grateful for the contribution of the late Mr. Frank LaMere, who graciously gave of his time to attend this event because of his deep concern for the health and wellbeing of his fellow Native Americans. 


\section{ABBREVIATIONS}

AI/AN: American Indian/Alaska Native; KWL: "Know, Want to know, and Learned"; NIH: National Institutes of Health; NSF: National Science Foundation; SEPA: Science Education Partnership Award; UNMC: University of Nebraska Medical Center; UNO: University of Nebraska at Omaha; UV: ultraviolet; YES: Youth Enjoy Science

\section{REFERENCES}

Allen-Ramdial, S. A., and Campbell, A. G. (2014). Reimagining the pipeline: Advancing STEM diversity, persistence, and success. Bioscience, 64, 612-618.

Baldwin, J., Janitz, A. E., Erb-Alvarez, J., Snider, C., and Campbell, J. E. (2016). Prevalence and mortality of melanoma in Oklahoma among racial groups, 2000-2008. Journal of the Oklahoma State Medical Association, 109, 311-316.

Becker, B. K., Schiller, A. M., Zucker, I. H, Eager, E. A., Bronner, L. P., and Godfrey, M. (2017). A day of immersive physiology experiments increases knowledge and excitement towards physiology and scientific careers in Native American students. Advances in Physiology Education, $41,127-144$

Black, W. C., and Wiggins, C. (1985). Melanoma among southwestern American Indians. Cancer, 55, 2899-2902.

Burgess, D. (2012). iBioSeminars: Mentoring students of color. Retrieved from www.ibiomagazine.org/issues/december-2012-issue/david-burgess.html.

Burnette, C. E., Roh, S., Liddell, J., and Lee, Y. S. (2019). American Indian women cancer survivor's needs and preferences: community support for cancer experiences. Journal of Cancer Education, 34, 592-599.

Carr, E., and Ogle, D. (1987). KWL plus: A strategy for comprehension and summarization. Journal of Reading, 30, 626-631.

CDC Centers for Disease Control and Prevention. (2019). Cancer Health Disparities among American Indians and Alaska Natives. Retrieved from https://www.cdc.gov/cancer/ healthdisparities/what_cdc_is_doing/aian.htm

Chang, M. J., Sharkness, J., Hurtado, S., and Newman, C. B. (2014). What matters in college for retaining aspiring scientists and engineers from underrepresented racial groups. Journal of Research in Science Teaching, 51, 555-580.

Dennis, J. M., Phinney, J. S., and Chuateco, L. I. (2005). The role of motivation, parental support, and peer support in the academic success of ethnic minority first-generation college students. Journal of College Student Development, 46, 223-236.

Eagan, M. K. Jr., Hurtado, S., Chang, M. J., Garcia, G. A., Herrera, F. A., and Garibay, J. C. (2013). Making a difference in science education: the impact of undergraduate research programs. American Education Research Journal, 50, 683713.

Freeman, S., Eddy, S. L., McDonough, M., Smith, M. K., Okoroafor, N., Jordt, H., and Wenderoth, M. P. (2014). Active learning increases student performance in science, engineering, and mathematics. Proceedings of the National Academy of Sciences of the United States of America, $111,8410-8415$
Graham, M. J., Frederick, J., Byars-Winston, A., Hunter, A. B., and Handelsman, J. (2013). Science education. Increasing persistence of college students in STEM. Science, 341, $1455-1456$.

Guillory, R. M., and Wolverton, M. (2008). It's about family: Native American student persistence in higher education. The Journal of Higher Education, 79, 58-87.

Hofstein, A., and Rosenfeld, S. (1996). Bridging the gap between formal and informal science learning. Studies in Science Education, 28, 87-112.

Holm, J. E., Vogeltanz-Holm, N., Poltavski, D., McDonald, L. (2010) Assessing health status, behavioral risks, and health disparities in American Indians living on the northern plains of the U.S. Public Health Reports, 125, 68-78.

Hsieh, H.-F., and Shannon S. E. (2005). Three approaches to qualitative content analysis. Qualitative Healthcare Research, $15,1277-1288$.

Hunter, A.-B., Laursen, S. L., and Seymour, E. (2007). Becoming a scientist: the role of undergraduate research in students' cognitive, personal, and professional development. Science Education 91, 36-74.

Hurtado, S., Newman, C. B., Tran, M. C., and Chang, M. J. (2010). Improving the rate of success for underrepresented racial minorities in STEM fields: insights from a national project. New Directions for Institutional Research, 2010, 5-15.

King, A., Staffieri, A., and Adelgais, A. (1998). Mutual peer tutoring: effects of structuring tutorial interaction to scaffold peer learning. Journal of Educational Psychology 90, 134.

Liddell, J. L., Burnette, C. E., Roh, S., and Lee, Y. S. (2018). Healthcare barriers and supports for American Indian women with cancer. Social Work in Health Care, 47, 656673.

Lopatto, D. (2004). Survey of undergraduate research experiences (SURE): first findings. Cell Biology Education, 3, 270277.

Maarouf, M., Zullo, S. W., DeCapite T, and Shi V. Y. (2019). Skin cancer epidemiology and sun protection behaviors among Native Americans. Journal of Drugs in Dermatology, 18, 420-423.

Marcinko, T. (2016). More Native American doctors needed to reduce health disparities in their communities. AAMC News, 14

Merchant, J. L., and Omary, M. B. (2010). Underrepresentation of underrepresented minorities in academic medicine: the need to enhance the pipeline and the pipe. Gastroenterology, 138, 19-26.

National Research Council. (2005). Assessment of NIH Minority Research and Training Programs: Phase 3. Washington, D.C.: National Research Council (NRC) Committee for the Assessment of NIH Minority Research Training Programs. Washington, DC: National Academy of Sciences. Retrieved from https://www.ncbi.nlm.nih.gov/books/ NBK22669/

National Research Council. (2007). Taking science to school: Learning and teaching science in grades K-8. Washington, DC: National Academies Press. Retrieved from https://www.nap.edu/login.php?record id $=11625$ \&page $=$ https $\% 3 \mathrm{~A} \% 2 \mathrm{~F} \% 2 \mathrm{Fwww}$.nap.edu $\% 2 \mathrm{~F}$ download $\% 2$ F 11625 
National Research Council. (2010). Surrounded by science: learning science in informal environments. Washington, D.C.: National Academies Press. Retrieved from https://www. nap.edu/catalog/12614/surrounded-by-science-learning-science-in-informal-environments

National Science Board. (2018). Science \& Engineering Indicators 2018. Retrieved from https://www.nsf.gov/ statistics/2018/nsb20181/report/sections/higher-education-in-science-and-engineering/graduate-education-enrollment-and-degrees-in-the-united-states\#s-e-doctoral-degrees.

Osborne, J., Simon, S., and Collins, S. (2003). Attitudes towards science: A review of the literature and its implications. International Journal of Science Education, 25,1049-1079.

Page, S. (2007). The difference. Princeton: Princeton University Press.

Prunuske, A. J., Wilson, J., Walls, M., and Clarke, B. (2013). Experiences of mentors training underrepresented undergraduates in the research laboratory. CBE-Life Sciences Education, 12, 403-409.

Rajput, A., Faizi, S. A., Nir, I., Morris, K. T., Fahy, B., Russell, J., and Wiggins, C. (2014). Pediatric melanoma in New Mexico American Indians, Hispanics, and non-Hispanic whites, 1981-2009. The American Journal of Surgery, 207, 412-416.

Sheridan, P. M., Szczepankiewicz, S. H., Mekelburg, C. R., and Schwabel, K. M. (2011). Canisius college summer science camp: combining science and education experts to increase middle school students' interest in science. Journal of Chemical Education, 88, 876-880.

Shoo, B. A., and Kashani-Sabet, M. (2009). Melanoma arising in African-, Asian-, Latino-, and Native-American populations. Seminars in Cutaneous Medicine and Surgery, 28, 96-102.

Stake, J. E., and Mares, K. R. (2005). Evaluating the impact of science-enrichment programs on adolescents' science motivation and confidence: the splashdown effect. Journal of Research in Science Teaching, 42, 359-375.

Thomas, D. A., and Ely, R. J. (1996). Making differences matter: a new paradigm for managing diversity. Harvard Business Review 75, 79-90.

Tinto, V. (2003). Learning better together: The impact of learning communities on student success. Higher Education Monograph Series, 1, 1-8. 